\title{
Genesis of a Wood Harvesting B2B Software Platform
}

\author{
Jaakko Vuolasto $^{(凶)}$ and Kari Smolander \\ Software Engineering, LUT University, Lappeenranta, Finland \\ \{jaakko.vuolasto, kari.smolander\}@lut.fi
}

\begin{abstract}
Digital platform research has focused mostly on global platforms, where the users of the platform are consumers. Business-to-business (B2B) digital platforms have received less attention. This study observes and provides an early report on a digital platform for forestry, bringing together forest companies, contractors, and forest machine manufacturers. The platform started in Finland, but it has begun to extent its scope to international markets as well. We present some early insights about the birth of the platform and the factors that have contributed to its success in the beginning. We also describe some aspects present in B2B platform governance and related forces. Finally, we provide a preliminary outlook of possible future directions of the platform and its ecosystem.
\end{abstract}

Keywords: Digital platforms · Governance · Platform emergence ·

Business-to-business platforms

\section{Introduction}

Digital platforms play an increasingly important role in the everyday life of consumers and businesses. Ghazawneh and Henfridsson [7] define platforms as a codebase providing a set of core functions for modules interoperating with it. A platform becomes more valuable both to its owner and its users when more and more users start using it. This network effect [6] can be direct or indirect.

Platforms can be created with a plan or they can evolve over time. In either case, a successful platform needs a coordinating party, a platform leader. This leadership is about both technology and business [5]. A key task of the leader is to govern the platform, keep it healthy, robust, growing, and offer niches for the parties involved [11]. The key element of governance is decision-making, defining who can make and what decisions [16]. A complementor then provides innovations and solutions that add value to the users of the platform [6].

SDKs, APIs, and related documentation are typical tools that the platform owner provides for application developers. These boundary resources [7] are the interface of the platform for complementors and also users. Boundary resources can be further classified into application, development, and social boundary resources [2]. 
Existing research has various viewpoints to governance. For example, Parker et al. [14] present laws, norms, architecture, and markets of as the elements of platform governance. Ghazawneh and Henfridsson [7] discuss boundary resources as methods of governance. Wareham et al. [18] describe tensions and how they are addressed in ecosystem governance. Wang and Burton-Jones [17] examine how static governance structures and dynamic actions interact and even co-constitute each other. Huber et al. [9] present a process theory of how rules and especially values of an ecosystem affect value co-creation and governance costs. A systematic way of evaluating governance status in different areas and a set of governance practices in the form of a maturity model is provided by Jansen [10].

There is an abundance of studies on global platforms like Apple iOS and Google Android. There are also many studies of business-to-business (B2B) platforms, for example $[15,18]$. A key characteristic of platforms in B2B world is separating the ownership of a resource from the value it creates [14]. Another is the global vs. regional perspective; a B2B platform operating in a certain geographic region may face limitations due to the nature of the region or the industry it serves. These local, regional and ownership issues are less studied.

This study approaches these issues with a case study of a digital platform for harvesting and silviculture operations, "Platform" from here on. The Platform connects forest companies (acting as "Service Buyers"), contractors working for them ("Contractors"), and forest machine manufacturers. Service Buyers require stable raw material flow for their factories or business partners. To achieve this, they use Contractors that own the forest machines and operate locally or regionally. Contractors aim to meet the requirements set by Service Buyers and optimize the usage of their forest machines. These two stakeholder groups have tight business relationships and sometimes deviating interests.

The research is in its early phase; this paper delivers some initial results and describes the case. Our research question is the following: what kind of aspects are present in B2B platform governance during its first years. The rest of this paper is structured so that Sect. 2 describes the research design and Sect. 3 the Platform participants and the components of the ecosystem around it. First insights to the research are presented in Sect. 4. Section 5 concludes the paper with an outlook of possible directions for future research.

\section{Research Design}

The focus is in a single platform, its participants, their interactions, and its governance. While the emphasis of this research is the Platform in Finland, the Platform itself is part of the Software Company's global portfolio.

We used Grounded Theory as the research method [4]. Our aim was to understand the phenomenon in its natural environment, by using multiple sources of information: interviewing platform stakeholders and observing publicly available documentation. We targeted the first round of 29 interviews mainly towards the Software Company, Service Buyers (SB), and Contractors (Table 1). The interviews were semi-structured and performed remotely due to COVID-19 restrictions. The interviews were transcribed, and the transcriptions were analyzed with coding. 
Table 1. First round of interviews

\begin{tabular}{|c|c|}
\hline Organization & Role \\
\hline Consulting Firm & Project Manager \\
\hline Contractor 1: harvesting, large, single SB & Account Manager \\
\hline Contractor 2: silviculture, large, multiple SBs & Manager \\
\hline Contractor 3: harvesting, large, multiple SBs & Manager \\
\hline Contractor 4: harvesting, large, single SB & CEO \\
\hline Contractor 5: silviculture, small, single SB & CEO \\
\hline Contractor 6: harvesting, small, single SB & CEO \\
\hline Contractor 7: harvesting, large, single SB & CEO \\
\hline Educational Institution & Teacher, Harvesting \\
\hline Machine manufacturer & Technical Customer Support Manager \\
\hline Service Buyer A & Senior Vice President, Development \\
\hline Service Buyer A & ICT Solution Designer \\
\hline Service Buyer B & System Specialist \\
\hline Service Buyer C & Development Manager \\
\hline Service Buyer C & Development Specialist \\
\hline Service Buyer C & Team Lead, Information Management \\
\hline Service Buyer D & SVP, Innovation and Development \\
\hline Service Buyer D & Solution Architect \\
\hline Service Buyer D & Development Manager, Harvesting \\
\hline Service Buyer D & Operations Manager \\
\hline Service Buyer E & Manager \\
\hline Service Buyer F & Manager \\
\hline Software Company & Product Owner \\
\hline Software Company & Service Manager \\
\hline Software Company & Service Manager \\
\hline Software Company & Product Owner \\
\hline Software Company & General Manager \\
\hline Software Company & Key Account Manager \\
\hline Wood procurement R\&D company & CEO \\
\hline
\end{tabular}

The observed documentation consisted of two communication standards $[19,20]$ that provide the foundations for the Platform boundary resources, and a set of regulations created by the Finnish Forest Industry [12] that provides the rules regarding forest machine data ownership and usage. 
Grounded theory is about interacting with the data and comparing data, codes, and emerging concepts [3]. In this study the comparison is still in its early phase: we performed the first round of interviews during February and March of 2021. While the analysis is in progress, some of the first emerging concepts are presented here.

\section{Platform Description}

\subsection{Participants}

There are about 25 Service Buyers using the Platform in Finland. These include publicly listed large companies, a state-owned enterprise, and Forestry Management Associations. The number of Contractors using the Platform is currently around 800 in Finland. For a Contractor it is mandatory to use the Platform when contracting with a Service Buyer using the Platform. A special subgroup of Contractors are Educational institutions. They train new forest machine drivers and use the Platform as part of the training.

Software Company is the platform leader. Additionally, it is also a Platform Complementor while developing systems for the Service Buyers using the Platform.

Forest Machine Manufacturers make harvesters and forwarders. A harvester is used to fell and cut trees in preferred lengths. A forwarder is used to transport the logs to an intermediate storage. They have control systems that are integrated to the Platform. About ten manufacturers have presence in the Finnish market.

Platform Complementors develop solutions for the Platform. This refers to the makers of the information systems of Service Buyers or control systems of forest machines.

There are two special organizations in the ecosystem. Finnish Forest Centre ${ }^{1}$ is a state-funded organization that collects and provides data about the forests in Finland, advices forest owners, and enforces forestry legislation. It has a central role in forestry related information systems in Finland, as it provides the Finnish Forest Data Standards [19], open data sets, APIs, and related tools.

Metsäteho ${ }^{2}$ is a R\&D company owned by forest industry organizations Finland. It has coordinated the creation of recommendation on the ownership, use and processing of data in forest machines [12]. It is also the Finnish coordinator of the StanForD standard [20].

\subsection{Components of the Ecosystem}

In the core of the Platform are features for planning, executing, and reporting harvesting and silviculture operations. The features are divided into client applications, common services for them, and an integration solution. Software Company has retained the development of all client applications to itself, while providing an API for other ecosystem participants, utilizing the Finnish Forest Data Standards [19]. Consumers of this API are the ERP systems of the Service Buyers.

\footnotetext{
${ }^{1} \mathrm{https} / / /$ www.metsakeskus.fi/en.

2 https://www.metsateho.fi/briefly-in-english/.
} 
ERP systems of Service Buyers tap into the Platform using the API mentioned above. There are Service Buyers whose ERP is provided by the same Software Company that is the Platform Owner. Additionally, there are Service Buyers in the Ecosystem, whose ERP is provided by another vendor. These complementing vendors were not interviewed in the first round.

Each forest machine manufacturer has a control system that steers the hardware of the machine. This control system interacts with the Platform client using the StanForD standard [20], either a text based older version or a more recent XML version. Both use files for information exchange.

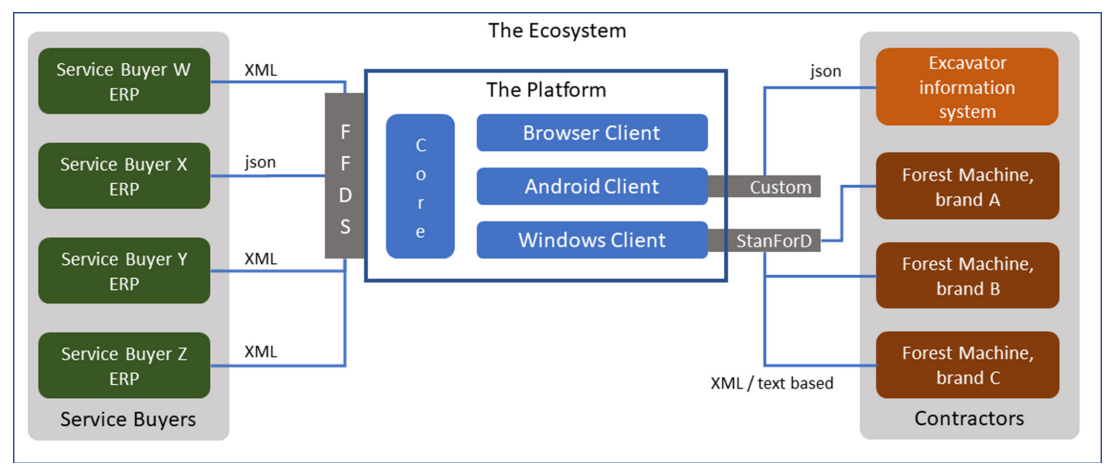

Fig. 1. The Platform and the ecosystem around it

The components of the ecosystem are presented in Fig. 1. Integrations with Service Buyer ERPs and forest machine control systems were implemented already during the initial implementation project. A more recent addition is the integration with an excavator information system used in planting of seedlings. The API based on Finnish Forest Data Services and the StanForD file-based integration are currently the boundary resources that the Platform offers. An example of a social boundary resource is a regular meeting with the Machine Manufacturers, organized by the Software Company.

\section{First Insights}

\subsection{Platform Genesis}

The Platform started out as a joint project of three Service Buyers to optimize their business processes with contractors. The companies created a common requirements specification and through a public procurement chose the Software Company for design, implementation and running the service.

Design specifications of the Platform were written in 2013 and the implementation project started in 2014. The first production deployments were in 2016, and production use gradually expanded during the following years, so that by 2019 all of the three founding Service Buyers had their harvesting and silviculture operations running on the Platform. 
The first years of the Platform have been a success. Most of the interviewees saw that the Platform has fulfilled its purpose well or at least reasonably. The use of the Platform has expanded both in Finland and internationally. While it is obligatory for a Contractor of Service Buyers to use the Platform, several interviewed Contractors mentioned that they would use it even if it was optional. The Platform has replaced the previous separate Service Buyer specific systems with a single solution. This has helped in optimizing the use of heavy machinery. For instance, Contractors are able to plan and execute their work so that machines operating in a certain area can now be used in working sites for different Service Buyers, which was very difficult or even impossible with the previous separate systems.

The founders had a common interest in creating an outsourced service. Although the founding Service Buyers are also competitors, they saw the benefits in developing a solution to a pre-competitive area. Instead of trying to create an industry-wide solution at once, two founding Service Buyers agreed first with each other and then a third one joined the venture. It also helped that the information systems of Service Buyers serving the same purposes as the Platform required renewal.

There were communication standards $[19,20]$ in place that helped creating the boundary resources to ERP and control systems. The recommendations about the forest machine data [12] and guidelines for following competitive legislation - created by the founders - can be viewed as examples of self-governance in [8]. Finally, the founders had positive experiences from a similar platform in wood logistics, also developed and run by the Software Company.

The founding Service Buyers had a strong role in the beginning. Having created the requirement specifications, they steered the development and governed the emerging ecosystem. As part of the agreement there is a framework for governance. It specifies rules for common development, decision-making structures, and for example the service level agreement in Finland. It was initially presented in 2013 as a part of the procurement documents. It was further developed during the implementation project and tested both in the first deployments and during the first years in production.

\subsection{Current Aspects to Governance}

Joining the Platform is rather straightforward. For a Contractor to enter the Platform two agreements are required: first with a Service Buyer about the contracting work, and second with the Software Company about using the Platform. A new Service Buyer can join the Platform by a negotiation with the Software Company. In this process it must be made sure that the conditions specified in the guidelines are met.

Adding new features to the Platform is more problematic. It was mentioned in the interviews that the needs of the Contractors should be the major driver of the Platform development. It seems that the requirements coming from Contractors are not getting through as well as expected. At least the following aspects have surfaced during the initial analysis.

Service Buyers and Contractors. The founding Service Buyers are established large companies with IT departments and routines for the customer-supplier dialogue. When they need a new feature on the Platform, they are more qualified to argue for their case. 
At the same time the Contractors are a heterogenous group. One-man company or a company having a fleet of 30 machines can have very different interests and abilities to influence the development of the Platform. The Contractors are the largest user group, but they represent the minority in the decision-making structures. The Software Company is expected to act as a balancer.

Slow Development. Day-to-day operation of the Platform is considered stable and satisfactory. However, development of new features or improvements in the Platform receives critique. Compared to exclusive software development, single vendor for a single customer, Service Buyers saw the Platform development progressing slower. Complexity meaning a greater number of participants - was identified as one reason, but the shortage of development resources of the Software Company was mentioned as well.

Finland and International. Although the focus of interviews was in Finland, the international aspect came also up. This is natural, as the potential market for the Platform in Finland is limited by the amount of Service Buyers and Contractors. It is one of the features of this B2B market: Contractor operates in a certain region and has a limited number of Service Buyers as its customers. Although the Software Company recognized the potential of the international market already in the very beginning, the implementation has not been without problems. There are differences in requirements and business processes in different geographic regions.

\subsection{Looking Ahead: Role of Complementors}

The number and types of Complementors are currently somewhat limited. In spite of that, the Software Company has clearly the leadership as described in [13] and it has the critical mass in Finland. The possible directions from here are interesting: as the regional market has its limits, geographic expansion is one way, which the Software Company has already pursued. Another possibility is to open the ecosystem more, which means emphasizing the role of Complementors. This will be a strategic decision for the Software Company - while growing, it needs to maintain control and protect its business interests. Understanding the value creation came up often in the interviews of the Software Company, as a prerequisite to introducing new Complementors to the ecosystem. However, controlling the ecosystem too tightly can result in lack of generativity and innovations, as reported in [1].

\section{Conclusions}

The case provides a classical setting: a platform leader balancing governance actions. The Service Buyers had a strong role in the beginning - a power shift to Software Company is well on its way, but perhaps not yet complete. A key issue is hearing the voice of Contractors.

Observing and analyzing B2B digital platform governance can help understanding the transformation of the industry. As timber markets, actors, and their interplay are not 
the same everywhere, geographic expansion is not a trivial option. Introducing more complementors to an existing ecosystem is not easy either.

The analysis of the results of the first interviews will continue, combined with a second targeted round towards Contractors and Complementors. A potential future direction for research is the role of the Software Company as both the leader and a Complementor; what kind of scenarios are possible with the current setting and with opening the ecosystem more. Data economy as an enabler for ecosystem self-renewal deserves attention. Also, a possible research avenue is in demarcation within the ecosystem: what is developed in the core of the Platform and what kind of features are implemented in the periphery.

\section{References}

1. Bazarhanova, A., et al.: Love and hate relationships in a platform ecosystem: a case of Finnish electronic identity management. Presented at the January 3 (2018). https://doi.org/10.24251/ HICSS.2018.187

2. Bianco, V.D., et al.: The role of platform boundary resources in software ecosystems: a case study. In: 2014 IEEE/IFIP Conference on Software Architecture, pp. 11-20 (2014). https:// doi.org/10.1109/WICSA.2014.41

3. Charmaz, K.: Grounded theory methods in social justice research. In: The SAGE Handbook of Qualitative Research, pp. 359-380. SAGE (2011)

4. Corbin, J.: Basics of Qualitative Research: Techniques and Procedures for Developing Grounded Theory. SAGE, Los Angeles (2015)

5. Gawer, A., Cusumano, M.: How companies become platform leaders. MIT Sloan Manag. Rev. 49(2), 28-35 (2008)

6. Gawer, A., Cusumano, M.A.: Industry platforms and ecosystem innovation. J. Prod. Innov. Manag. 31(3), 417-433 (2014). https://doi.org/10.1111/jpim.12105

7. Ghazawneh, A., Henfridsson, O.: Balancing platform control and external contribution in third-party development: the boundary resources model. Inf. Syst. J. 23(2), 173-192 (2013). https://doi.org/10.1111/j.1365-2575.2012.00406.x

8. Gorwa, R.: What is platform governance? Inf. Commun. Soc. 22(6), 854-871 (2019). https:// doi.org/10.1080/1369118X.2019.1573914

9. Huber, T.L., et al.: Governance practices in platform ecosystems: navigating tensions between cocreated value and governance costs. Inf. Syst. Res. 28(3), 563-584 (2017). https://doi.org/ 10.1287/isre.2017.0701

10. Jansen, S.: A focus area maturity model for software ecosystem governance. Inf. Softw. Technol. 118, 106219 (2020). https://doi.org/10.1016/j.infsof.2019.106219

11. Jansen, S., Cusumano, M.: Defining software ecosystems: a survey of software platforms and business network governance. In: Software Ecosystems: Analyzing and Managing Business Networks in the Software Industry, vol. 879, (2013). https://doi.org/10.4337/9781781955628. 00008

12. Metsäteho: Metsäkonetiedon omistusta, käyttöä ja käsittelyä koskevat periaatteet. http://www. metsateho.fi/metsakonetieto-suositus/. Accessed 14 Oct 2020

13. Moore, J.F.: Predators and Prey: A New Ecology of Competition (1993). https://hbr.org/1993/ 05/predators-and-prey-a-new-ecology-of-competition

14. Parker, G.G., et al.: Platform Revolution: How Networked Markets Are Transforming the Economy and How to Make Them Work for You. W. W. Norton \& Company, New York (2016) 
15. Shestakofsky, B., Kelkar, S.: Making platforms work: relationship labor and the management of publics. Theory Soc. 49(5-6), 863-896 (2020). https://doi.org/10.1007/s11186-020-094 $07-\mathrm{z}$

16. Tiwana, A., et al.: Research commentary-Platform evolution: coevolution of platform architecture, governance, and environmental dynamics. Inf. Syst. Res. 21(4), 675-687 (2010). https://doi.org/10.1287/isre.1100.0323

17. Wang, G., Burton-Jones, A.: Rethinking IT governance structure and action. In: ICIS 2020 Proceedings (2020)

18. Wareham, J., et al.: Technology ecosystem governance. Organ. Sci. 25(4), 1195-1215 (2014). https://doi.org/10.1287/orsc.2014.0895

19. Finnish Forest Data Standards. https://www.metsakeskus.fi/fi/avoin-metsa-ja-luontotieto/suo rakayttoaineistot/metsatietostandardit. Accessed 09 Apr 2021

20. StanForD. https://www.skogforsk.se:443/english/projects/stanford/. Accessed 10 Apr 2021

Open Access This chapter is licensed under the terms of the Creative Commons Attribution 4.0 International License (http://creativecommons.org/licenses/by/4.0/), which permits use, sharing, adaptation, distribution and reproduction in any medium or format, as long as you give appropriate credit to the original author(s) and the source, provide a link to the Creative Commons license and indicate if changes were made.

The images or other third party material in this chapter are included in the chapter's Creative Commons license, unless indicated otherwise in a credit line to the material. If material is not included in the chapter's Creative Commons license and your intended use is not permitted by statutory regulation or exceeds the permitted use, you will need to obtain permission directly from the copyright holder.

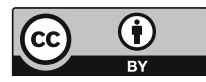

